\title{
Classifictcação dos pobres: questões, construção e análise
}

GLAYTON SIRILO DO VALE FURTADO"

\section{Resumo}

O artigo insere o posicionamento social através de variáveis como status da ocupação e a própria ocupação dos indivíduos, obtidos na PNAD, como forma de descrever e analisar a pobreza brasileira sob um enfoque sociológico. O respaldo teórico para tal empreendimento provém basicamente das contribuições de Erik Olin Wright e, no Brasil, de José Alcides Figueiredo Santos.

A linha de pobreza foi utilizada na delimitação dos pobres dentro de cada posição social. Com isso foi observado em quais posições o percentual de pobres é mais significativo e indiretamente, captou-se a vantagem ou desvantagem de estar em uma posição social, tais como a condição de subalternidade ou de qualificação, ou seja, deter ativos importantes para escapar da situação de pobreza.

Palavras-chave: Pobreza. Desigualdade social. Classe social.

\footnotetext{
* Mestre em Ciências Sociais Pela UFJF. Analista de dados do CAEd/UFJF (Centro de Políticas Públicas e Avaliação da Educação)
} 


\section{Introdução}

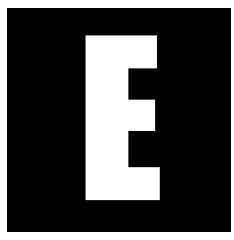

ste artigo descreve a pobreza brasileira de uma outra forma, mais próxima das Ciências Sociais, mas sem perder a importante contribuição já fornecida pelas demais áreas envolvidas no estudo desse fenômeno. Para isso, apresenta, além de discussões teóricas que tentam elucidar tal mecanismo de geração e perpetuação da pobreza, a construção de um instrumento analítico aplicado às variáveis da PNAD que possibilitaria uma forma complementar às linhas de pobreza, ultrapassando a mera mensuração e descrevendo as posições sociais dos pobres.

Tenta-se, então, compreender melhor como esses indivíduos obtêm seus rendimentos e como a circunstância domiciliar pode acentuar ou atenuar a renda deles. Não foi medida e estudada a repartição da renda dentro do domicílio; no entanto, como a renda utilizada foi a domiciliar per capita, supõe-se agregação e, em alguma medida, a repartição da mesma pelos membros do domicílio. Esse meio pelo qual o indivíduo obtém seus rendimentos, bem como sua posição social, nos ajuda a entender melhor as questões da pobreza e da desigualdade de renda. O resultado de um estudo recente (Dillon Soares, 2006) aponta para o fato de que a redução da desigualdade de rendimentos (Gini), ocorrida entre 2001 e 2004, foi em grande parte (3/4) decorrente da desconcentração de rendimentos via mercado de trabalho. $\mathrm{O}$ fato de um indicador de desigualdade apresentar redução não significaria uma diminuição direta da pobreza. Contudo, como o Brasil apresenta concentração de renda muito forte e renda per capita acima da linha de pobreza, se ocorre redistribuição de renda dos segmentos de maiores concentrações para as camadas mais pobres, indiscutivelmente existe uma contribuição para redução da pobreza via redução da desigualdade, que, como constatou a pesquisa, ocorreu principalmente através do mercado de trabalho. 
Esse fato reforça a importância de se construir um modelo analítico baseado em posições socioeconômicas dos trabalhadores assalariados pobres, inserções precárias, exclusão e relações de dependência ou inatividade. Tal empreendimento interessa não só para compreender melhor o que está acontecendo e delinear campos de atuação para as políticas públicas, mas também para captar os diversos condicionamentos que ocorrem, variando de acordo com a posição em que o indivíduo está localizado. Em outras palavras, para verificar de alguma forma se o que a pessoa tem determina o que ela obtém (Wright, 2005).

Não se contraria o fato de que a pobreza, no caso brasileiro, está intrinsecamente ligada à desigualdade em suas diversas manifestações. Dessa maneira, a redução da desigualdade via mercado de trabalho ajusta-se à abordagem de Wright (1994).

Em relação às posições sociais e à pobreza, Wright (1994) especificamente aponta para os trabalhadores pobres em decorrência da exploração e expropriação, ou seja, para aqueles que principalmente receberiam baixos salários. Além dos trabalhadores existiria uma camada formada pelos oprimidos que não têm acesso a recursos importantes como terra, capital e trabalho, a denominada underclass.

Em Marklund (1990), existem estudos realizados em países nórdicos que apontam a existência de um curso contínuo de pessoas pobres da classe trabalhadora para a underclass e vice-versa. Essas movimentações de pobres entre posições de classe são sociologicamente relevantes na investigação de fatores estruturais da pobreza brasileira.

Seguindo esse procedimento, tem-se, grosso modo, a classe dos trabalhadores pobres e o excedente (excluídos). Entretanto, ao aplicar a linha de pobreza e categorizar com base na vasta gama de ocupações da PNAD, espera-se que o universo fique mais refinado, propiciando a subdivisão da classe trabalhadora pobre e da underclass. 
Tal proposta de operacionalização e construção do instrumento leva em consideração que:

A especificidade da estrutura de classes no país parece materializar-se, de modo particular, na geração de uma grande heterogeneidade socioeconômica em um hipertrofiado segmento de auto-emprego e na constituição de formas exacerbadas de destituição, dentro e fora do universo do trabalho assalariado, quando não de exclusão do sistema social de produção (Figueiredo Santos, 2005a, 33).

Avalia-se a hipótese de que a natureza da inserção corporificada pelo tipo, status da ocupação e o controle de ativos importantes, entre outros, determinaria diferentes chances de ser ou não pobre. Parece óbvio que a posição social de um empregador minimize fortemente a chance de o mesmo ser pobre, contudo, tal clareza se transforma em incerteza quando comparamos um trabalhador doméstico com um trabalhador por conta própria.

Há uma preocupação com a necessidade de superação do paradigma da renda para se estudar a pobreza, tendo em vista, principalmente, o fato de ser um instrumento unidimensional e sintetizador de um problema multidimensional que é a pobreza.

Dessa maneira, neste artigo foi defendida a inclusão das posições sociais que trazem junto a noção de classe social, exploração e opressão. No entanto, pelo menos até o momento, a abolição por completo da renda ainda não parece algo viável, ou seja, os desafios de criar conceitos alternativos ao paradigma da renda operacionalmente permanecem grandes (Bourguignon, 2006,101). O próprio Amartya Sen, integrante do novo paradigma, admite a relevância da renda, embora também destaque a importância de fatores pessoais e do meio para estabelecer seu mecanismo conceitual de capacidade de funcionamentos: tendo uma alta renda determinará, fornecerá outras coisas, o que ajuda a alcançar uma ampla capacidade para funcionar (Sen, 2006,35). 


\section{Construindo a classificação}

A construção da classificação socioeconômica (posição social) para se estudar a pobreza foi realizada utilizando-se de diversas variáveis da PNAD 2004. No momento, serão descritos sucintamente algumas variáveis e procedimentos utilizados na criação da classificação. Se houver necessidade, à medida que os dados das tabelas forem analisados, algumas intervenções futuras sobre os processos poderão ser ressaltadas.

As posições sociais engendradas da população ocupada foram derivadas da classificação socioeconômica feita por Figueiredo Santos (2005a). O autor, utilizando-se das PNADs, construiu sua classificação com base em transformações realizadas particularmente por meio das variáveis originais de posição na ocupação, que corresponde à noção sociológica de status do emprego (empregado, empregador etc.), tipo de estabelecimento, setor de atividade e ocupação. Nos estudos de mobilidade social, em particular dada a dificuldade de mensurar diretamente a origem de classe, a ocupação pode servir como substituto (proxy) para a posição de classe. Deve-se considerar que a ocupação é, hoje, um dos principais indicadores da posição social dos indivíduos, e tem sido amplamente utilizada para definir esquemas de classes, tanto entre neomarxistas como entre neoweberianos (Scalon, 1998).

A ocupação ganha força diante de outros aspectos, como a profissão ou o nível educacional, ainda que tais características possam estar implícitas em diversas ocupações. Tal fato fundamenta-se na medida em que ter apenas uma profissão, como, por exemplo, ser formado em Ciências Sociais, não determina a forma como o indivíduo vai obter a renda. Sob esse ponto de vista, o enquadramento de posição de classe provavelmente deve ser mais afetado pela posição na ocupação e pela própria ocupação, ou seja, pelo que de fato o indivíduo exerce na sociedade para sobreviver. Isso muitas vezes pode ter um caráter distinto de sua formação ou qualificação. 
Como o interesse deste artigo está na pobreza, foram feitas agregações e desagregações a partir das sintaxes do autor (Figueiredo Santos, 2005a), além da criação de novas categorias (indivíduos não ocupados). As diferenciações entre os ocupados têm origem na variável V4706, que representa a posição na ocupação do trabalho principal da semana de referência para pessoas de 10 anos ou mais de idade (PNAD, 2004). Essa variável foi recodificada e passou a ser representada pelas categorias: empregado, empregado doméstico, conta própria, empregador, trabalhador na produção para o próprio consumo, trabalhador na construção para o próprio uso e não remunerado, além do próprio missing que servirá mais à frente para classificar os não ocupados. O próximo passo foi a desagregação de algumas dessas posições através de recodificações condicionadas a outras variáveis.

As nuances relacionadas às ocupações permitiram que se fizesse uma diferenciação dos ocupados com base nos critérios de Wright (1997), ou seja, propriedades de ativos de capital, controle diferenciado de ativos de qualificação e relação com o exercício de autoridade dentro da produção. No entanto, como o foco está na pobreza, foram inseridos ainda outros critérios, como a diferenciação de agrícola e não agrícola em algumas categorias, além da contribuição para a previdência social como fator diferenciador da posição de trabalhador formal e informal.

As primeiras dezesseis categorias são formadas de ocupados (ver quadro 1). Da categoria aposentado ou pensionista federal até beneficiários de outros rendimentos (inclusive) há algumas situações de não ocupados que foram classificados através da recodificação do missing da V4706 com base em variáveis que apontavam para as respectivas situações de inatividade. Nas posições de beneficiários de programas de transferência de renda e BPC-LOAS (Benefício de Prestação Continuada), a classificação foi feita de forma indireta. Utilizando-se de variáveis do arquivo de domicílios, foi possível reclassificar o missing da variável V4706, signifi- 
cando, portanto, que as composições dessas posições referem-se a indivíduos que vivem em um domicílio onde pelo menos uma pessoa recebe ou algum programa de transferência de renda ou, no caso da posição BPC-LOAS, esse benefício.

Essas duas categorias foram criadas somente porque a PNAD de 2004 ofereceu essa possibilidade através do suplemento dos programas sociais. Em relação aos programas de transferência de renda houve um procedimento de agregação dos programas: Auxílio-Gás, Bolsa-Família, Cartão-Alimentação do programa Fome Zero, Bolsa-Alimentação, BolsaEscola, Bolsa-família, PETI (Programa de Erradicação do Trabalho Infantil) e outros programas federais, estaduais e municipais. No final, com exceção de Não remunerado que já era uma categoria própria da variável V4706, as outras foram criadas a partir de recodificações condicionadas do missing restante dessa mesma variável. 
Quadro 1 - Posições sociais criadas

\begin{tabular}{|l|}
\hline Empregador agrícola \\
\hline Empregador não agrícola \\
\hline Classe média \\
\hline Forças armadas \\
\hline Conta própria agrícola \\
\hline Conta própria não agrícola capitalizado \\
\hline Conta própria não agrícola com qualificação \\
\hline Empregados qualificados e supervisores \\
\hline Trabalhador formal \\
\hline Trabalhador informal \\
\hline Trabalhador elementar agrícola \\
\hline Trabalhador elementar não agrícola \\
\hline Conta própria precário \\
\hline Empregado doméstico \\
\hline Trabalhador no autoconsumo \\
\hline Trabalhador na própria construção \\
\hline Aposentado ou pensionista federal \\
\hline Aposentado ou pensionista de outros tipos \\
\hline Rentista (recebe aluguel) \\
\hline Dependente de doação de não morador \\
\hline Beneficiário de outros rendimentos \\
\hline $\begin{array}{l}\text { Pessoa de domicílio dependente de progra- } \\
\text { mas de transferência de renda }\end{array}$ \\
\hline Pessoa de domicílio beneficiário de BPC- \\
LOAS (direito) \\
\hline Desempregados \\
\hline Não remunerado \\
\hline Afazeres domésticos \\
\hline Estudantes \\
\hline Sem atividade ou sem declaração \\
\hline
\end{tabular}




\section{Delimitando a classificação: a linha de pobreza}

No quadro 1 temos as posições sociais criadas desde as mais privilegiadas até as menos favorecidas, contudo, é necessário indicar as composições dos pobres nessas posições. Tal passo implica a utilização de fronteiras de rendimentos, procedimento que é comumente empregado através da linha de pobreza.

Para se chegar aos valores da linha de pobreza, isto é, ao limiar que separa os pobres dos não pobres, o ponto de partida é o cálculo da linha de indigência que está diretamente ligada às questões de sobrevivência física, principalmente alimentar. Sendo assim, a melhor mensuração é a regionalizada com base no consumo observado. Essa metodologia permite que se chegue aos valores monetários necessários para suprir o consumo calórico mínimo indicado pela FAO.

A primeira etapa consiste em determinar, para a população em questão, quais são suas necessidades nutricionais. A etapa seguinte objetiva estabelecer, a partir das informações de pesquisa de orçamentos familiares, a cesta alimentar de menor custo que atenda às necessidades nutricionais estimadas. O valor correspondente a essa cesta é a linha de indigência (Rocha, 2005,50).

Até aqui se tem o limiar de miseráveis e não miseráveis, mas como o foco do trabalho situa-se na dicotomia de pobres e não pobres, o próximo passo é o cálculo da linha de pobreza. Uma vez satisfeitas as necessidades calóricas mínimas, Rocha (2005) utiliza as informações das despesas não alimentares para famílias de baixa renda contidas no Sistema Nacional de Índices de Preços ao Consumidor (SNIPC). É importante salientar que não existe consenso para determinar, do ponto de vista empírico, o mínimo necessário de consumo não alimentar, sendo, portanto, uma estimativa. Os valores das linhas de pobreza e de indigência de 2004 calculados por Sônia Rocha (2006) estão no anexo 2. No caso do artigo foram considerados apenas os valores da linha de pobreza. 
Existe uma discussão acerca de qual rendimento deveria ser utilizado para o cálculo da linha de pobreza, o qual poderia ser tanto a renda individual quanto o rendimento familiar ou domiciliar. Nos dois últimos casos, levar-se-ia em conta o somatório total da renda dos membros da família ou domicílio e a divisão do resultado pelo número total de pessoas, ou seja, obteríamos o rendimento familiar ou domiciliar per capita. Dessa forma,

A variável relevante quando se trata de medir pobreza sobre a ótica da renda é a renda familiar ou domiciliar per capita, que resulta da repartição solidária dos rendimentos de todas as origens (trabalho, aposentadorias, pensões, doações, transferências, aluguéis, juros, etc.) recebidos por todos os membros da família ou domicílio (Rocha, 2006, 13).

Nem todos concordam que o melhor cálculo da linha de pobreza deva se basear na renda domiciliar per capita. De acordo com Arriaga$\mathrm{da}$, as formas tradicionais de medição da pobreza que privilegiam a renda familiar obscurecem a pobreza dos membros menos favorecidos do domicílio: mulheres, jovens, crianças e idosos (Arriagada, 2005, 105). De maneira semelhante,

Uma linha de pobreza que ignora completamente as características individuais não consegue fazer justiça às nossas verdadeiras preocupações sobre o básico da pobreza, a insuficiência de capacidade devida a meios econômicos inadequados. Seguidamente será sensato agrupar os indivíduos em categorias particulares (relacionadas com classe, sexo, grupo ocupacional, status do emprego, e assim por diante) (Sen, 2001a, 175).

A opção adotada neste trabalho foi a da renda domiciliar para determinar quem é ou não pobre. Essa escolha justifica-se por se considerar o domicílio e a repartição da renda no domicílio como mais próximos da representação da realidade brasileira.

Os valores das linhas de pobreza foram calculados pela pesquisadora Sônia Rocha (anexo 2) e já levam em consideração os diferentes custos 
de vida do Brasil, além de características alimentares peculiares de cada região. A partir desses valores e de posse dos dados da PNAD 2004, foi criada a variável linha de pobreza (VLPOBRE); o procedimento de "alimentação" das categorias " 0 " não pobre e "1" pobre foi feito através de várias recodificações condicionadas do missing da nova variável. Para tal, houve a utilização da variável UF para diferenciar o estado, V4728 para diferenciar a região urbana da rural, V4727 para determinar as regiões metropolitanas, e V4621, que é a variável de renda domiciliar per capita. Com as diversas combinações dessas variáveis foi possível levar em consideração os valores regionalizados e chegar aos parâmetros de pobres e não pobres.

\section{Análise sociológica da classificação}

A análise (tabela 1) busca responder de que maneira e em que medida a natureza da inserção, o status da ocupação e o controle de ativos importantes determinariam em grande parte as chances de ser ou não pobre. A princípio, o leitor poderia se questionar por que uma classificação dos pobres deveria conter posições cujo número de pobres é tipicamente pequeno, como, por exemplo, os empregadores. Tal recurso busca incorporar uma ferramenta importante das Ciências Sociais, que é a comparação, considerando que em alguma medida essas categorias de não pobres auxiliem, lançando luz e contrastando com posições sociais, em que os pobres são mais representativos, revelando, por exemplo, a contribuição de deter ativos importantes para escapar da pobreza.

Dessa forma, ao se dividir as porcentagens de pobres internas às categorias (dentro de parênteses) pelo percentual total de pobres da classificação $(31,6 \%)$, chegaremos ao índice de representação, o que nos permite aferir em que medida e qual a importância de pertencer àquela posição para se tornar pobre ou não. Assim, do ponto de vista analítico, quanto 
mais próximo de zero, menores serão as chances daquele indivíduo de se tornar pobre. Próximo de 1,00, as chances são consideráveis e, acima de 1,00, vão se elevando quanto maior o valor do índice de representação.

As demonstrações serão extraídas da tabela 1 e, para não se tornarem cansativas, serão enfatizados apenas os aspectos mais relevantes ou que têm implicações sociológicas para a análise da pobreza brasileira.

Com isso, constata-se facilmente que as quatro primeiras posições sociais são tipicamente de não pobres, tanto pela composição interna das categorias quanto pelo índice de representação que foi menor na classe média $(0,06)$, acompanhada de perto pelos empregadores não agrícolas $(0,09)$. Logo, são as posições menos prováveis de encontrarmos pobres; em seguida vêm os empregadores agrícolas $(0,18)$, empregados qualificados e supervisores $(0,22)$, e forças armadas $(0,25)$. 
Tabela 1 - Cruzamento de posições sociais por linha de pobreza, contribuição para a pobreza geral e composição interna (entre parênteses) nas posições. Acompanha índice de representação da posição dos pobres.

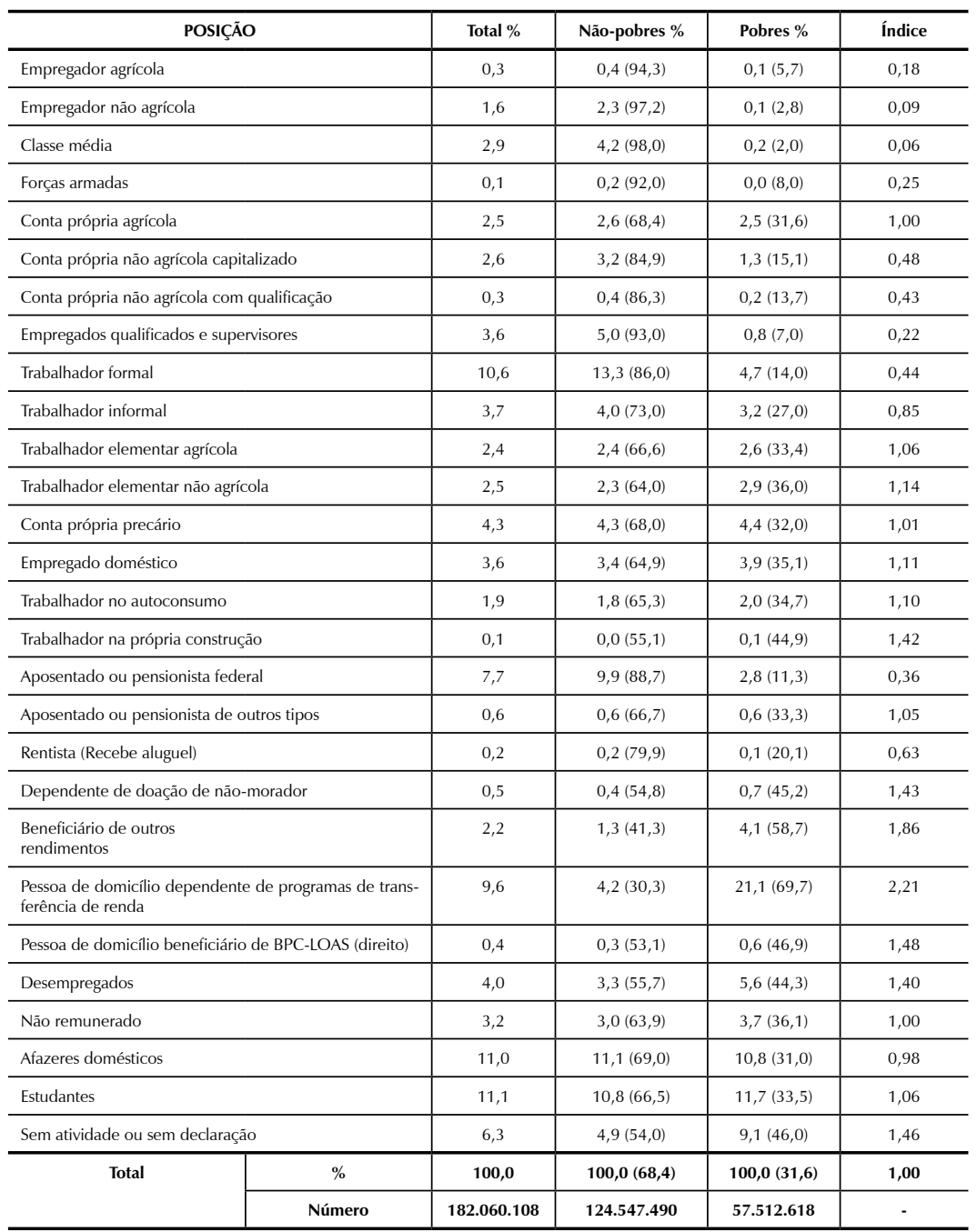

Fonte: Elaborado com base no IBGE. PNAD 2004. 
Quando se adentra nas categorias de conta próprias, as chances de o indivíduo se tornar pobre passam a ser significativas. Estamos, então, entrando propriamente nas posições sociais dos pobres. Observando o índice de representação, os conta próprias precários $(1,01)$ são acompanhados de maneira muito próxima pelos conta próprias agrícolas $(1,00)$. Notoriamente, o fato de pertencer a qualquer uma das duas posições não ameniza a tendência para a pobreza, o que também pode ser constatado pela contribuição das posições na composição da pobreza geral, de forma que os conta próprias precários representam 4,4\%, e os conta próprias agrícolas, $2,5 \%$. Essa situação é amenizada fortemente, reduzindo em mais da metade, nos conta próprias não agrícolas capitalizados $(0,48)$ e nos conta próprias não agrícolas com qualificação $(0,43)$. Do ponto de vista da pobreza, existe uma heterogeneidade importante na posição dos conta próprias que, se não fosse desagregada, dificilmente seria captada. Assim, nos capitalizados que possuem algum tipo de estabelecimento ou veículo, a contribuição para a pobreza geral é de $1,3 \%$ e naqueles com qualificação $(0,2 \%)$. Aí, encontram-se principalmente os técnicos de nível médio.

A circunstância da renda domiciliar per capita, utilizada no recorte da linha de pobreza, aponta para questões demográficas, pois, como se sabe, nas áreas rurais que abrigam a maior parte dos conta próprias agrícolas, a taxa de natalidade é maior que no meio urbano. Entre inúmeros fatores, destaca-se que o conhecimento e a facilidade de acesso aos métodos contraceptivos estão mais distantes dessa realidade. Assim, hipoteticamente, eles contam com famílias maiores, e a renda do indivíduo no contexto domiciliar seria repartida em um maior número de partes, contribuindo para o agravamento da situação de destituição.

Para os empregados domésticos, o índice de representação passou a ser de 1,11 , posição que acentua as chances de o indivíduo ser pobre. A contribuição para a pobreza geral também é relevante (3,9\%). Uma expli- 
cação possível advém da baixa complexidade da função, que não exige ativos de qualificação como nível educacional médio ou superior, exigindo, no máximo, alguma experiência. A posição também é marcada pela intensa subalternidade e, apesar de contar com modificações favoráveis recentes na legislação trabalhista, como o registro em carteira, ainda se situa precariamente em relação ao direito de trabalhadores formais como o pagamento de hora-extra e FGTS.

Ao considerar as quatro categorias dos trabalhadores em conjunto (formal, informal, elementar agrícola e elementar não agrícola), constatase que $13,4 \%$ da pobreza no Brasil é formada pela categoria agregada dos trabalhadores, perdendo somente para a posição das pessoas que recebem transferências de renda (21,1\% da pobreza no Brasil). De alguma forma, isso pode ser interpretado como uma das consequências da exploração que atua sobre as classes trabalhadoras, correspondendo à análise da pobreza de Wright (1994). Utilizando somente as posições de trabalhadores (formal e informal), com trabalhadores típicos, fica notória a diferença entre os trabalhadores formais e informais no que tange às chances de ser pobre, pois, apesar de ambos contribuírem significativamente para a pobreza no Brasil, $4,7 \%$ e 3,2\% respectivamente, é mais provável um trabalhador informal ser pobre $(0,85)$ do que um trabalhador formal $(0,44)$. Em relação aos trabaIhadores elementares agrícolas e aos elementares não agrícolas (manutenção, conservação, ajudantes de obra etc.), fica evidente uma aproximação dessas categorias com a elevação interna das porcentagens de pobres, nos agrícolas (33,4\%) e nos não agrícolas (36\%).

Em termos de probabilidade de ser pobre de acordo com a posição social há uma oposição de sentido pois, nos trabalhadores formais $(0,44)$ e informais $(0,85)$, provavelmente, ela é diminuída, ao passo que, nos trabalhadores elementares agrícolas $(1,06)$ e elementares não agrícolas $(1,14)$, a posição acentua a chance de ser pobre. A análise indica para o 
fato de serem indivíduos que não possuem nenhuma qualificação; exercem funções que não exigem grande experiência e habilidade, em geral completamente braçais. Eles não detêm nenhum capital e nenhum poder nas relações de produção; logo, se o que a pessoa tem, determina o que ela obtém (Wright, 2005), facilmente podemos perceber essa colocação do pesquisador norte-americano em categorias como essas. As pessoas possuem muito pouco, quase nada, em termos de ativos, implicando de alguma forma o que esses indivíduos obtêm, ou seja, baixos rendimentos, tornando-se presas fáceis da pobreza.

Especificamente em relação à posição dos dependentes dos programas de transferência de renda, está localizada a maior chance de ser pobre da classificação, com o índice de representação de 2,21. Essa posição também lidera tanto internamente, com $69,7 \%$ de pobres, quanto em contribuição para a pobreza no Brasil $(21,1 \%)$. É possível deduzir duas considerações que, de certa forma, são paradoxais. Primeiro, esperavase um número maior de pobres nessa posição, ou seja, os 30,3\% de não pobres que recebem renda dos programas de transferência poderiam demonstrar um grupo de indivíduos que estão se beneficiando de alguma falha de operacionalização ou de delimitação do público-alvo. Segundo, apesar de receberem a transferência de renda, os 69,7\% continuam abaixo da linha de pobreza, isto é, o valor recebido pelo domicílio na partição de seus membros é insuficiente para retirá-los da pobreza. É impossível dizer se os 30,3\% de não pobres consistem em um erro de alvo e monitoramento, ou se são os pobres que saíram da pobreza através dos programas, pois apenas o acompanhamento dessa posição, por um período mais longo, poderia elucidar melhor essa questão.

Os desempregados são responsáveis por 5,6\% da pobreza no Brasil e correspondem, na proposição teórica de Erik Olin Wright (1994), a uma espécie de subclasse que é oprimida. Faltam-lhes ativos fundamen- 
tais (educação, qualificação etc.) para obtenção de renda e, mesmo que eles os tenham, carecem de oportunidades de colocação no mercado de trabalho, ou de recursos para ter o próprio negócio. Dessa forma estabelecem uma precária e tênue relação com a obtenção de renda.

Em relação aos não remunerados $(1,00)$, afazeres domésticos $(0,98)$ e os estudantes $(1,06)$ podemos constatar uma certa aproximação das chances de serem capturados pela pobreza. No caso dos não-remunerados, pode ser que muitos participem, por exemplo, de empreendimentos familiares, e eles não realizam nenhuma retirada. Quando ela ocorre, não é feita de maneira sistemática nem é captada no período de referência da realização da coleta de dados da PNAD. No caso de afazeres domésticos e dos estudantes, fica nítida uma considerável contribuição para a pobreza no Brasil, respectivamente 10,8\% e 11,7\%. Em ambos os casos, temos aparentemente dois grupos vulneráveis que devem contar com as repartições de renda internas no domicílio, o que nem sempre é suficiente para retirá-los da pobreza. Assim, no primeiro caso, pode-se ter uma pobreza com viés de gênero e, no segundo, uma pobreza com viés de idade, focada nos mais jovens que estudam.

De 28 posições criadas para se estudar a pobreza brasileira, dezesseis possuem uma chance igual ou maior de se tornar pobre, em outras palavras, apresentam índice de representação igual ou maior que 1,00. Dessas, duas são formadas por conta próprias, cinco são posições de trabalhadores (incluindo os empregados domésticos), uma de aposentados e pensionistas de outros tipos, e oito de dependentes ou beneficiários de programas do governo ou de doações de outras pessoas de fora ou de dentro do domicílio. Clareia-se a percepção de que a pobreza brasileira é fortemente composta por situações e circunstâncias de posições oprimidas, em que não se possui o mínimo de ativos necessários. Quando o possuem, não encontram oportunidades, como, por exemplo, a inserção 
no mercado de trabalho. Isso se agrava mais se considerarmos o trabalhador de autoconsumo e o da própria construção como posições também de opressão, pois não estão sendo explorados, uma vez que ninguém está se apropriando dos frutos de suas atividades, a não ser eles mesmos.

Um exercício de agregação das posições feitas (tabela 2) auxilia na interpretação de condições gerais e comuns das posições dos pobres. Em empregadores e classe média ampliada temos empregadores agrícolas, empregadores não agrícolas, classe média, forças armadas e empregados qualificados e supervisores. Entre conta própria estão os conta próprias agrícolas, não agrícolas capitalizados, não agrícolas com qualificação e os rentistas (pessoas que recebem aluguel) que, de alguma forma, se aproximam de uma espécie de conta própria, porque não são empregadores nem trabaIhadores e possuem uma forma de obter rendimento que não os coloca como dependentes ou sem rendimentos. Na posição de trabalhador, há o trabalhador formal e informal, ou seja, o trabalhador típico. Para abrigar as posições de ocupados mais destituídos, foi criada a posição de ocupações precárias, na qual foram agregados os trabalhadores elementares agrícolas, não agrícolas, autoconsumo e própria construção, além dos conta próprias precários e empregados domésticos. Na posição de aposentados e pensionistas, foi acrescentada a categoria das pessoas que vivem em domicílio beneficiado pelo BPC-LOAS, além da unificação das duas diferenciações de aposentados e pensionistas existentes na classificação anterior.

Em dependentes e sem rendimentos, agregam-se todas as situações de opressão, nas quais as pessoas não detêm rendimentos ocupacionais, são dependentes de programas do governo, de doação de não morador, ou da repartição interna da renda domiciliar. Assim, incluem-se aqui dependentes de doação de não morador, beneficiários de outros rendimentos, pessoas que vivem em domicílios dependentes de programas de transferência de renda, desempregados, não remunerados, afazeres domésticos, estudantes e sem atividade ou sem declaração. 
Tabela 2 - Cruzamento de posições sociais agregadas por linha de pobreza, contribuição para a pobreza geral e composição interna (entre parênteses) nas posições. Acompanha índice de representação da posição dos pobres.

\begin{tabular}{|c|c|c|c|c|c|}
\hline \multicolumn{2}{|c|}{ POSIÇÃO } & Total \% & Não-pobres \% & Pobres \% & Índice \\
\hline \multicolumn{2}{|c|}{ Empregadores e classe média ampliada } & 8,6 & $12,1(95,5)$ & $1,2(4,5)$ & 0,14 \\
\hline \multicolumn{2}{|c|}{ Conta própria } & 5,7 & $6,5(77,5)$ & $4,1(22,5)$ & 0,71 \\
\hline \multicolumn{2}{|c|}{ Trabalhador típico } & 14,3 & $17,3(82,6)$ & $7,9(17,4)$ & 0,55 \\
\hline \multicolumn{2}{|c|}{ Ocupações precárias } & 14,8 & $14,2(66,0)$ & $15,9(34,0)$ & 1,07 \\
\hline \multicolumn{2}{|c|}{ Aposentados ou pensionistas } & 8,7 & $10,8(85,4)$ & $4,0(14,6)$ & 0,46 \\
\hline \multicolumn{2}{|c|}{ Dependentes e sem rendimentos } & 47,9 & $39,1(55,9)$ & $66,9(44,1)$ & 1,40 \\
\hline \multirow[t]{2}{*}{ Total } & $\%$ & 100,0 & $100,0(68,4)$ & $100,0(31,6$ & 1,00 \\
\hline & Número & 182.060 .108 & 124.547 .490 & 57.512 .618 & - \\
\hline
\end{tabular}

Fonte: Elaborado com base no IBGE. PNAD 2004.

Os conta próprias vivenciam uma situação intermediária de opressão e exploração, variando de acordo com os ativos e com sua capacidade de mobilização. Logo, se os trabalhadores com 0,55 de índice de representação requerem atenção, os conta próprias com 0,71 requerem mais ainda, porque muitos já podem estar próximos das situações de opressão e das ocupações precárias. A preocupação prioritária, no entanto, não é com a exploração, mas com os oprimidos, pois situações como essas ameaçam a vida de alguns indivíduos pela falta do mínimo necessário como a alimentação e, pelas análises, pode-se concluir que, para resolver e retirar esses indivíduos dessa circunstância aguda de pobreza, um mínimo de ativos produtivos faz toda diferença. Estratégias como a construção de ativos, uma espécie de empowerment que Oliver e Grant (2000) apontam, permitiriam, no mínimo, uma situação próxima a dos conta próprias. Por fim, apesar da gravidade de alguns aposentados que recebem o mínimo vigente, o índice de 0,46 demonstra uma vantagem para se escapar da pobreza, o que ocorre de forma muito mais intensa nos empregadores e na classe média ampliada, com 0,14. 
O percurso até aqui nos permite algumas considerações. Percebese a evolução de chance de se tornar pobre de acordo com as posições sociais e o tipo de relação que estas mantêm no sistema produtivo. Se enfocarmos a opressão e a exploração como as duas características de Wright (1994) para a geração da pobreza, constata-se que as posições estão alijadas do sistema produtivo (oprimidos), ou seja, a underclass é representada pelos dependentes e sem rendimentos e compõe 66,9\% da pobreza brasileira. Os trabalhadores (típicos) representam a situação de exploração imposta pelos baixos salários e remunerações pagas pelos empregadores. No entanto, encontram-se em uma situação relativamente "confortável", se comparados aos oprimidos, o que pode ser comprovado também pela nítida menor representatividade na pobreza geral. Contudo, devem ser vistos com atenção, pois podem ser capturados a qualquer momento pelas situações de opressão, como o desemprego, por exemplo.

Teoricamente, existem algumas diferenciações no tocante à underclass que poderiam ser relevantes para a interpretação dos dados. Ao que parece, para Marklund (1990), o conceito de marginalização estaria mais próximo da underclass de Wright (1994), ou seja, da classe de pessoas que estariam excluídas do sistema, pois lhes faltaria acesso a recursos básicos. Já a underclass, para Marklund, seria uma perspectiva que defende que há um contínuo curso de pessoas da classe trabalhadora para os pobres e dos pobres para a classe trabalhadora (Marklund, 1990, 127).

Se observarmos o índice de representação das posições sociais da tabela 2, vamos constatar uma hierarquia de vulnerabilidade, de forma que possivelmente existe um fluxo entre as posições. Assim, se os dependentes e sem rendimentos $(1,40)$ como uma espécie de underclass, e os trabalhadores típicos $(0,55)$, fossem considerados como classe trabalhadora, parte dos integrantes das ocupações precárias $(1,07)$ poderia estar em trajetória tanto ascendente como descendente. Mas, trata-se apenas 
de uma hipótese que só poderia ser comprovada através de estudos temporais de mobilidade social da classe trabalhadora para a underclass e vice-versa.

\section{Conclusões}

Primeiro, constata-se uma variação das chances de ser pobre paralela e praticamente proporcional às posições, isto é, quanto mais capital, qualificação ou poder o indivíduo detém no processo de produção, tanto menores são as chances de o mesmo ser pobre. Isso pode ser ilustrado tanto pelas posições de empregadores (detêm capital), classe média (alta qualificação ou poder), forças armadas e empregados qualificados e supervisores, quanto pelo outro extremo: pessoas em situação de opressão, como os desempregados e os que dependem dos programas de transferência, e estão em situação muito mais crítica com maiores chances de serem pobres do que posições em que o indivíduo detém algo, apesar de ser explorado, como é o caso dos trabalhadores. Até mesmo os conta próprias precários desfrutam de circunstâncias mais favoráveis, pois minimamente prestam algum serviço ou revendem produto em via pública. É uma posição precária, mas na qual o indivíduo detém minimamente alguma coisa (habilidade, mercadoria) que é capaz de minimizar as chances de ser pobre. Isso confirma a hipótese de que o status da ocupação e o controle de ativos da posição influenciam diretamente nas chances de o indivíduo ser ou não pobre.

Segundo, fica clara a relevância do corte formal $\mathrm{X}$ informal, ou ainda de direitos (legal) $X$ humanitário (sem legislação) como fundamentais nas categorias que permitiram essa comparação para atenuar ou acentuar as chances de ser pobre. Na categoria trabalhador formal (critério daquele que contribui para instituto de previdência), as chances de ser pobre 
são reduzidas quase pela metade em relação aos trabalhadores informais. Da mesma forma ocorre com os beneficiários de BPC-LOAS, que é um benefício assistencial pago para pessoas com deficiência e com renda familiar per capita inferior a um quarto do salário mínimo. Independentes de contribuição e assegurados pela Constituição Federal, os beneficiários apresentam uma porcentagem bem menor de pobres quando comparados às pessoas que recebem benefícios de programas de transferência de renda que, em si, é um recurso de caráter humanitário e emergencial com valores mais baixos do que os do BPC-LOAS, que é de um salário mínimo.

Por último, de três categorias nas quais existe a diferenciação de agrícola e não agrícola em duas (empregador agrícola e conta própria agrícola) há um aumento percentual das chances de ser pobre, praticamente o dobro quando se trata da condição de agrícola. ${ }^{1}$

Neste artigo foi realizado um exercício para se estudar a pobreza brasileira através do emprego do conceito de classe social proveniente das Ciências Sociais. Esse conceito foi empregado indiretamente de maneira empírica na construção das posições sociais para se estudar a pobreza. Contudo, este trabalho é apenas o começo para se clarear a compreensão dos posicionamentos sociais dos pobres, e existem notoriamente outras variáveis como gênero e raça que não podem ser desprezadas.

1 De alguma forma essa interpretação aproxima-se do estudo do IETS, que coloca a agricultura e extração como o setor de atividade que, no período de 1992 a 2004 apresentou em todos os anos a menor renda real média do trabalho principal. 


\section{Classification of the poor: questions, formulation and analysis}

\section{Abstract}

The article includes the placement through social variables such as status of the occupation and the occupation of individuals, obtained in the PNAD, as a way to describe and analyze poverty Brazilian under a sociological approach. The theoretical support for this enterprise comes mainly from contributions by Erik Olin Wright and Brazil by José Alcides Figueiredo Santos.

The poverty line was used in the demarcation of the poor within each state, with which it was observed heading in the percentage of poor is more significant, indirect captures is the advantage or disadvantage of being in a social position, such as the condition of inferiority, qualification, that is, hold significant assets to escape out of poverty.

Keywords: Poverty. Social inequality. Social class.

\section{Referências}

ARRIAGADA, Irma. Dimensiones de la pobreza y políticas desde una perspectiva de gênero. Revista de la Cepal, no5, 2005.

BOURGUIGNON, François. From income to endowments: the difficult task of expanding the income poverty paradigm. In: GRUSKY, David; KANBUR, Ravi. (Edited). Poverty and inequality. California: Stanford University Press, 2006

DILLON SOARES, Sergei S. Distribuição de renda no Brasil de 1976 a 2004 com ênfase no período entre 2001 e 2004. Texto para discussão n.o 1166, IPEA. 2006 FIGUEIREDO SANTOS, José Alcides. Uma classificação socioeconômica para o Brasil. Revista Brasileira de Ciências Sociais, vol.20, no 58, 2005a.

IBGE. Pesquisa nacional por amostra de domicílios - 2004. CD-ROM. Microdados. Rio de Janeiro, 2004.

IETS. Indicadores PNAD 1992-2004. Disponível em < http://www.iets.org.br/rubrique.php3?id_rubrique=94> acesso em dezembro de 2005 .

MARKLUND, Staffan. Structures of modern poverty. Acta Sociologica, no. 2, 1990.

OLIVER, Melvin O; GRANT, David M. The persistence of poverty In a changing world. In: BLAUL, Judith R. (ed.). The blacwell companion to sociology. Oxford: Blacwell, 2000. 
ROCHA, Sônia. Alguns Aspectos Relativos à Evolução 2003-2004 da Pobreza e da Indigência no Brasil. Disponível em <www.iets.org.br> acesso em Agosto de 2006.

.Pobreza no Brasil, afinal de que se trata? Rio de Janeiro: FGV, 2005.

SCALON, Maria Celi. Mapeando estratos: critérios para a escolha de uma classificação. Dados, v.41, no-2, 1998.

SEN, Amartya. Conceptualizing and measuring poverty. In: GRUSKY, David; KANBUR, Ravi. (Edited). Poverty and inequality. California: Stanford University Press, 2006.

.Desigualdade reexaminada. Rio de Janeiro: Record, 2001a.

WRIGHT, Erik Olin. Foundations of a neo-Marxist class analysis. In: WRIGHT, Erik Olin. (ed.). Approaches to class analysis. Cambridge: University Press, 2005.

. Class counts: comparative studies in class analysis. Cambridge: Cambridge University Press, 1997.

. Class analysis of poverty. In: Interrogating inequality: essays on class analysis, socialism and marxism. London: Verso, 1994.

\section{Anexo 1}

Renda Real Média de Cada Décimo da Distribuição no Brasil

\begin{tabular}{|c|c|c|c|c|c|c|c|c|c|c|}
\hline & 1995 & 1996 & 1997 & 1998 & 1999 & 2001 & 2002 & 2003 & 2004 & $2004^{* 1}$ \\
\hline Primeiro & 33 & 30 & 31 & 34 & 33 & 31 & 36 & 33 & 39 & 38 \\
\hline Segundo & 76 & 74 & 75 & 78 & 77 & 77 & 81 & 77 & 86 & 85 \\
\hline Terceiro & 114 & 113 & 114 & 118 & 114 & 116 & 119 & 115 & 125 & 123 \\
\hline Quarto & 156 & 158 & 157 & 161 & 156 & 159 & 162 & 156 & 168 & 165 \\
\hline Quinto & 206 & 210 & 209 & 212 & 205 & 209 & 212 & 204 & 218 & 215 \\
\hline Sexto & 268 & 275 & 275 & 278 & 268 & 274 & 277 & 267 & 282 & 278 \\
\hline Sétimo & 353 & 364 & 364 & 366 & 348 & 357 & 360 & 348 & 366 & 361 \\
\hline Oitavo & 491 & 512 & 509 & 510 & 484 & 493 & 494 & 473 & 493 & 488 \\
\hline Nono & 772 & 800 & 796 & 800 & 758 & 767 & 764 & 728 & 750 & 742 \\
\hline Décimo & 2272 & 2302 & 2310 & 2351 & 2204 & 2249 & 2230 & 2070 & 2098 & 2080 \\
\hline
\end{tabular}

Fonte: Elaborado pelo IETS com base na Pesquisa Nacional por Amostra de Domicílios (PNAD).

1 - A área rural da região norte do país, a exceção do estado de Tocantins passou a integrar a amostra em 2004.

Os resultados da coluna 2004* apresentam as estimativas para 2004 incorporando essa área.

2 - Valores expressos em Reais de 2004, utilizando o INPC para o deflacionamento. 


\section{Anexo 2}

Valor das Linhas de Pobreza e de Indigência (Valores per capita/por mês) -Setembro de 2004.

\begin{tabular}{|c|c|c|}
\hline Regiões e Estratos & Indigência & Pobreza \\
\hline \multicolumn{3}{|l|}{ Norte } \\
\hline Belém & 47,03 & 142,86 \\
\hline Urbano & 46,29 & 124,53 \\
\hline Rural & 30,81 & 62,47 \\
\hline \multicolumn{3}{|l|}{ Nordeste } \\
\hline Fortaleza & 48,84 & 140,35 \\
\hline Recife & 60,92 & 199,81 \\
\hline Salvador & 58,15 & 181,19 \\
\hline Urbano & 42,21 & 122,62 \\
\hline Rural & 36,67 & 73,96 \\
\hline \multicolumn{3}{|c|}{ Minas Gerais/Espírito Santo } \\
\hline Belo Horizonte & 51,79 & 175,24 \\
\hline Urbano & 44,64 & 117,82 \\
\hline Rural & 35,81 & 69,75 \\
\hline \multicolumn{3}{|l|}{ Rio de Janeiro } \\
\hline Metrópole & 67,53 & 209,78 \\
\hline Urbano & 49,02 & 130,52 \\
\hline Rural & 38,71 & 95,28 \\
\hline \multicolumn{3}{|l|}{ São Paulo } \\
\hline Metrópole & 66,64 & 250,79 \\
\hline Urbano & 54,39 & 160,25 \\
\hline Rural & 42,77 & 100,82 \\
\hline \multicolumn{3}{|l|}{ Sul } \\
\hline Curitiba & 47,83 & 168,54 \\
\hline Porto Alegre & 51,72 & 132,28 \\
\hline Urbano & 45,04 & 112,96 \\
\hline Rural & 35,52 & 76,15 \\
\hline \multicolumn{3}{|l|}{ Centro-Oeste } \\
\hline Brasília & 54,62 & 240,15 \\
\hline Goiânia & 53,52 & 222,86 \\
\hline Urbano & 46,57 & 169,69 \\
\hline Rural & 35,06 & 97,46 \\
\hline
\end{tabular}

Fonte: Rocha, Sônia (2006).

Recebido: 22/12/2008

Aceite final: 16/03/2009 